\title{
HLA AW19, B12 in immunoproliferative small intestinal disease
}

\author{
B. NIKBIN, M. BANISADRE, F. ALA, AND A. MOJTABAI \\ From the Iranian National Blood Transfusion Service and Taj Pahlavi Cancer Institute of Tehran \\ University (WHO Regional Reference Centre for study of IPSID and Oesophageal Carcinoma), Iran
}

SUMMARY A group of 21 patients with immunoproliferative small intestinal disease (IPSID), 10 with alpha heavy chain paraproteinaemia and 11 without it, were HLA typed. The results were compared with 35 disease controls and 120 normal controls. A significant increase of Aw19 and B12 antigens was noted among the patients compared with the control subjects. The high rate of association of both AW19 and B12 antigens in patients as compared with controls suggests a possible haplotype (Aw19, B12) association with IPSID.

The so-called 'Mediterranean' abdominal lymphoma now referred to as immunoproliferative small intestinal disease (IPSID) (WHO, 1975) is a disease of the young with a geographical distribution which shows that the overwhelming majority of cases reported have been of Mediterranean or Middle Eastern origin (Ramot et al., 1965; Eidelman et al., 1966; Rappaport et al., 1972; Shahid et al., 1975; Nasr et al., 1976; Zarrabi and Rosner, 1976). It is usually characterised by the cardinal symptoms and signs of chronic watery diarrhoea and steateorrhoea with abdominal pain and weight loss. Clubbing of fingers and toes is common. Small intestinal biopsy usually reveals villous atrophy and diffuse, massive plasmolymphocytic infiltration of the lamina propria together with involvement of mesenteric lymph nodes.

Analysis of the patient's serum and jejunal juice frequently demonstrates a fast-moving heterogeneous paraprotein essentially composed of an incomplete heavy-chain of IgA. Many cases do not conform to this pattern, however, and our series is marked by a considerable clinical and pathological heterogeneity.

The suggestion that a potentially reversible, premalignant stage of the disease exists (Ramot et al., 1965; Rogé et al., 1970) which, if untreated may rapidly progress to a malignant phase with a fatal outcome, makes early detection of the disease in susceptible population groups highly desirable. This, together with the peculiar geographical distribution of the disease, warrants a search for disease-associated environmental and genetic factors.

To our knowledge, no report on the relationship between HLA and IPSID has hitherto appeared in the literature. In the present study, which started about two years ago as part of a larger prospective project, 21 patients suffering from IPSID were HLA typed together with 35 disease and 120 healthy controls in order to discover any particular association that might exist.

\section{Methods}

\section{PATIENTS}

Fifty-six patients suffering from malabsorption syndrome or chronic diarrhoea along with 120 healthy controls were studied for the A, B, C antigens of the HLA system. The patients were typed blindly without any knowledge regarding aetiology of their malabsorption or diarrhoea. Out of these 56 cases, 21 were found to have IPSID either with alpha-chain protein in their sera (group I, 10 patients), or without it (group II, 11 patients). The remaining 35 cases of malabsorption due to other causes served as disease controls (group III) and 120 voluntary blood donors were used as healthy controls (group IV). Disease controls were all subjected to peroral jejunal biopsy and serum analysis (by radial immunoselection) in order to exclude IPSID.

TECHNIQUES

Using standard NIH lymphocytotoxicity test, 14 antigens for the A locus, 15 for the B locus, and 
five for the $\mathrm{C}$ locus were detected on the peripheral blood lymphocytes.

The antisera used were monospecific and mostly of local origin, although well-defined antisera from NIH and some from Eurotransplant were also used. At least three antisera were used for detection of each specificity.

\section{Results}

As shown in the Table, groups I and II both exhibited a significant increase in AW19 from the A-locus compared with control groups III and IV (P $<0.001)$. The former groups (I and II) also showed an increase in B12 from the B-locus compared with controls III and IV $(P<0.001)$. A relative increase in $\mathrm{B} 17$ in group II patients compared with all other groups was also noted.

The most significant finding, however, was the simultaneous presence of both AW19 and B12 antigens in patients compared with controls, which is suggestive of a haplotype association

The immediate family members of one patient from group I were also studied (Figure). The patient's 11 year old sister, and 54 year old mother shared high risk HLA antigens with her. Both were symptom-free, however, with no alpha-chain protein in their sera. Nevertheless, the patient's sister is still below the usual age of onset (15 to 30 years) and is being followed up.

\section{Discussion}

IPSID occurs relatively frequently in the Middle Eastern countries and the Mediterranean basin (Ramot et al., 1965; Eidelman et al., 1966; Rappaport et al., 1972; Shahid et al., 1975; Nasr et al., 1976; Zarrabi et al., 1976). However, our own studies on over 50 patients diagnosed during the past two years at Taj Pahlavi Cancer Institute, Tehran, have not

Table Distribution of HLA antigens observed more frequently in IPSID than in control groups

\begin{tabular}{|c|c|c|c|c|c|c|c|c|c|c|c|c|c|}
\hline \multirow{2}{*}{$\begin{array}{l}H L A \\
\text { specificities }\end{array}$} & \multicolumn{6}{|c|}{ Patients } & \multicolumn{4}{|c|}{ Controls } & \multirow[t]{2}{*}{$x^{2}$} & \multirow[t]{2}{*}{$P$} & \multirow[t]{2}{*}{$R R$} \\
\hline & \multicolumn{2}{|c|}{$\begin{array}{l}\text { Group I } \\
\text { (10 cases) }\end{array}$} & \multicolumn{2}{|c|}{$\begin{array}{l}\text { Group } I I \\
(11 \text { cases })\end{array}$} & \multicolumn{2}{|c|}{$\begin{array}{l}\text { Group } I+I I \\
(21 \text { cases })\end{array}$} & \multicolumn{2}{|c|}{$\begin{array}{l}\text { Group III } \\
\text { (35 cases) }\end{array}$} & \multicolumn{2}{|c|}{$\begin{array}{l}\text { Group IV } \\
\text { (120 cases) }\end{array}$} & & & \\
\hline $\begin{array}{l}\text { AW19 } \\
\text { B12 } \\
\text { Aw19+B12 }\end{array}$ & $\begin{array}{l}3 \\
4 \\
3\end{array}$ & $\begin{array}{l}30 \\
40 \\
30\end{array}$ & $\begin{array}{l}4 \\
3 \\
3\end{array}$ & $\begin{array}{l}36 \cdot 3 \\
27 \cdot 2 \\
27 \cdot 2\end{array}$ & $\begin{array}{l}7 \\
7 \\
6\end{array}$ & $\begin{array}{l}33 \cdot 3 \\
33 \cdot 3 \\
28 \cdot 5\end{array}$ & $\begin{array}{l}2 \\
2 \\
0\end{array}$ & $\begin{array}{l}6 \\
6 \\
0\end{array}$ & $\begin{array}{r}4 \\
13 \\
1\end{array}$ & $\begin{array}{r}3 \cdot 3 \\
10 \cdot 8 \\
0 \cdot 8\end{array}$ & $\begin{array}{r}22 \cdot 36 \\
7 \cdot 43 \\
28 \cdot 39\end{array}$ & $\begin{array}{l}<0.0001 \\
<0.001 \\
<0.0001\end{array}$ & $\begin{array}{r}15 \\
4 \\
48\end{array}$ \\
\hline
\end{tabular}

$\chi^{2}$ : Chi-square (comparison of groups I + II with groups III + IV).

RR: Relative risk.

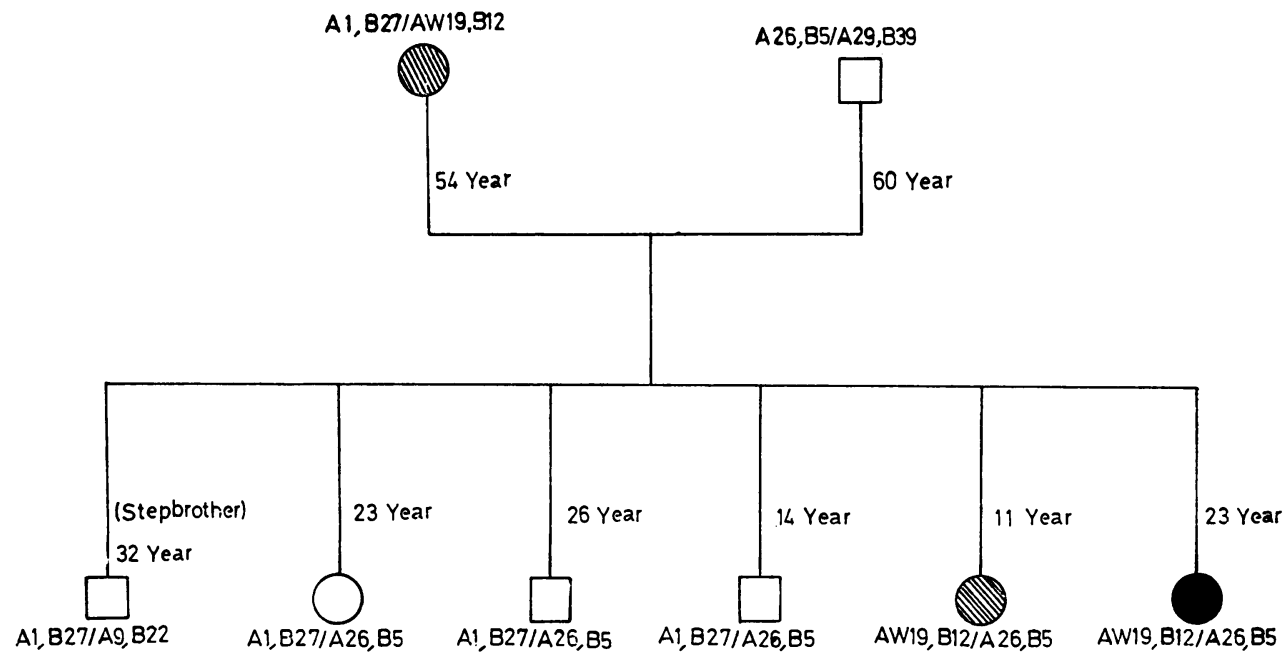

Figure Pedigree of the family of a patient suffering from small intestinal lymphoma and alpha-heavy chain disease. The patient is marked by a black circle, and other members sharing the same haplotype are shown by striped circles. 
shown a clustering of cases in any one particular region of the country (Banisadre, 1978). This makes population surveys for early detection of new cases difficult and unproductive, and, clearly, a search for factors associated with susceptibility to IPSID is highly desirable. Factors such as disease-associated HLA antigens may help identify individuals at high risk, particularly among immediate family members of patients. Those who appear to be at risk can then be followed up closely for development of early signs of the disease, which may still be potentially reversible (Report of a WHO Meeting of Investigators, 1976; Rogé et al., 1970). In this regard, a review of the literature revealed two reports of the familial incidence of IPSID. The first one, from Iran (Banihashemi et al., 1973), described three families with lymphoma in multiple family members. One of the families included a 22 year old girl and her 28 year old brother who developed IPSID within six months of each other, even though they had lived far apart. The second report (Maurer et al., 1976) described four brothers (all children between 2 and 7 years old) who all developed IPSID within a span of seven years. These findings raise the possibility of a genetic predisposition or immune deficiency which may pave the way for mutagenic or oncogenic stimuli in the environment.

In one family studied by us two members showed 'high risk' HLA antigens in common with the patient, and these members are being closely followed up.

The importance of association between HLA haplotype and disease has been emphasised before (Terasaki and Mickey, 1975). Our data and the family study of one of our patients in which the inheritance of AW19, B12 as haplotype was shown are suggestive of a significant association between HLA haplotype AW19, B12, and IPSID. Unfortunately, we still have insufficient data concerning lymphatic malignancies other than IPSID, although this is being collected and the findings will be re- ported later on. It remains to be established whether our findings are significant in terms of susceptibility to the disease or its course.

\section{References}

Banihashemi, A., Nasr, K., Hedayatee, H., and Mortazavec, H. (1973). Familial lymphoma including a report of familial primary upper small intestinal lymphoma. Blut, 26, 363-368.

Banisadre, M., Rashed, M. A., Navab, F., Ala, F., and Mojtabai, A. (1978). Paper presented at the Third International Symposium on Oncology, Tehran, Iran.

Eidelman, S., Parkins, A., and Rubin, C. E. (1966). Abdominal lymphoma presenting as malabsorption. A clinico-pathologic study of nine cases in Israel and a review of literature. Medicine (Balt.), 45, 111-137.

Maurer, H. S., Gotoff, S. P., Allen, L. and Bolan, J. (1976). Malignant lymphoma of the small intestine in multiple family members: association with an immunologic deficiency. Cancer, 37, 2224-2231.

Nasr, K., Haghighi, P., Bakhshandeh, K., Abadi, P., and Lahimgarzadeh, A. (1976). Primary upper small intestinal lymphoma. A report of $\mathbf{4 0}$ cases from Iran. American Journal of Digestive Diseases, 21, 313-323.

Ramot, B., Shahin, N., and Bubis, J. J. (1965). Malabsorption syndrome in lymphoma of small intestine. A study of 13 cases. Israel Journal of Medical Sciences, 1, 221-226.

Rappaport, H., Ramot, B., Hulu, N., and Park, J. K. (1972). The pathology of so-called Mediterranean abdominal lymphoma with malabsorption. Cancer, 29, 1502-1511.

Report of a WHO Meeting of Investigators (1976). Alpha chain disease and related small-intestinal lymphoma. Archives des Maladies de l'Appareil Digestif, 65, 591-607.

Rogé, J., Druet, P., and Marche, C. (1970). Lymphome méditerranéen avec maladie des chaînes alpha. Triple remission clinique, anatomique et immunologique. Pathologie et Biologie (Paris), 18, 851-858.

Shahid, M. J., Alami, S. Y., Nassar, V. H., Balikian, J. B., and Salem, A. A. (1975). Primary intestinal lymphoma with paraproteinemia. Cancer, 35, 848-858.

Terasaki, P. I., and Mickey, M. R. (1975). HL-A haplotypes of 32 diseases. Transplantation Reviews, 22, 105-119.

WHO (1975). Report: Alpha Heavy Chain Disease Meeting. Geneva, 10-13 November. WHO: Geneva.

Zarrabi, M. H., and Rosner, F. (1976). Middle Easter. intestinal lymphoma: report of a case and review of the literature. American Journal of Medical Sciences, 272, 101-119. 